\title{
Fabrication and optical simulation of vertically aligned silicon nanowires
}

\author{
M. K. Hossain ${ }^{1}$ B. Salhi ${ }^{1}$ - A. W. Mukhaimer ${ }^{1}$ - F. A. Al-Sulaiman ${ }^{1,2}$
}

Received: 21 October 2015/Accepted: 19 November 2015/Published online: 30 November 2015

(C) The Author(s) 2015. This article is published with open access at Springerlink.com

\begin{abstract}
Silicon nanowires (Si-NWs) have been considered widely as a perfect light absorber with strong evidence of enhanced optical functionalities. Here we report finite-difference time-domain simulations for $\mathrm{Si}-\mathrm{NWs}$ to elucidate the key factors that determine enhanced light absorption, energy flow behavior, electric field profile, and excitons generation rate distribution. To avoid further complexity, a single Si-NW of cylindrical shape was modeled on $\mathrm{c}-\mathrm{Si}$ and optimized to elucidate the aforementioned characteristics. Light absorption and energy flow distribution confirmed that Si-NW facilitates to confine photon absorption of several orders of enhancement whereas the energy flow is also distributed along the wire itself. With reference to electric field and excitons generation distribution it was revealed that Si-NW possesses the sites of strongest field distributions compared to those of flat silicon wafer. To realize the potential of Si-NWs-based thin film solar cell, a simple process was adopted to acquire vertically aligned Si-NWs grown on c-Si wafer. Further topographic characterizations were conducted through scanning electron microscope and tunneling electron microscope-coupled energy-dispersive spectroscopy.
\end{abstract}

M. K. Hossain

kamalhossain@kfupm.edu.sa

$\triangle$ B. Salhi

billel@kfupm.edu.sa

1 Center of Research Excellence in Renewable Energy (CORERE), King Fahd University of Petroleum and Minerals (KFUPM), Dhahran 31261, Kingdom of Saudi Arabia

2 Department of Mechanical Engineering, King Fahd University of Petroleum and Minerals (KFUPM), Dhahran 31261, Kingdom of Saudi Arabia
Keywords Fabrication - FDTD simulation - Photovoltaic solar cell $\cdot$ Silicon nanowires

\section{Introduction}

Silicon, a revolutionary element of the periodic table, is indeed not only perfect match for microelectronics, but also hold a well-studied and long-experiences for photovoltaics (PVs) (Xiao and Xu 2014; Green 2014). A healthy and incomparable revenue of more than $90 \%$ of PV solar cell market is a clear indication of this success. Silicon ( $\mathrm{Si}$ ) is plentiful and ubiquitous; 2nd most abundant material after Carbon on earth. It is also superior to other metals because of stability and non-toxicity in general. Conventional Si-based PV solar cells are made of planar junctions of p- and n-type Si. Because of relatively low light absorption, an efficient cell requires thick absorbing layer. To the extent, the absorbing layer needs to be of highpurity microelectronic-grade. This implies high cost of $\mathrm{Si}$ solar panel making the technology non-competitive in price with reference to conventional energy sources. Cost and efficiency are the two major avenues for PV technology to survive in solar cell market. In this concern, huge emphasize is being given to increase cell efficiency with novel PV designs and lower the cost of solar-grade $\mathrm{Si}$ materials via inexpensive Si production methods (Green 2014; Bolman et al. 2011).

One dimensional Si nanostructures, such as, Si nanowires (Si-NWs) have been emerged as an extremely attractive candidate due to their unique properties (Sachs 2011; He et al. 2012; Kelzenberg et al. 2010; Polman and Atwater 2012; Ozdemir et al. 2011; Zhao et al. 2004; Krogstrup et al. 2013; Yu et al. 2014). Apart from low-cost, Si-NWs have strong optical absorption in the solar 
spectrum, i.e., less than $1 \%$ equivalent of $\mathrm{Si}$ materials in Si-NWs can achieve the same amount of absorption absorbed by traditional planar wafer-based PV devices. SiNWs-based solar cells with radial $\mathrm{p}-\mathrm{n}$ junctions offer a short collection length for charge carriers, thus allowing the use of lower-quality Si materials. Si-NWs can be produced with excellent electrical characteristics. These advantages may substantially reduce the production cost of Si-NWbased solar cells while retaining efficiencies competitive with planar multicrystalline Si solar cells. Currently, several methods have been reported to grow Si-NWs vertically, viz., chemical vapor deposition (CVD), nanoparticles-assisted etching, reactive-ion etching (RIE), etc. (Yi et al. 2011; Krylyuk et al. 2010; Moutanabbir et al. 2011; Shin and Filler 2012; Zhong et al. 2011; Chen et al. 2010; Huang et al. 2008; Geyer et al. 2012; Yuan et al. 2012; Chang et al. 2012; Cho et al. 2011; Sainiemi et al. 2011; Garnett and Yang 2010; Zhu et al. 2009). The SiNWs prepared by these methods exhibit promising photoelectron conversion characteristics. By integrating appropriate preparation process of Si-NWs into the well-developed production lines, mass produced low-cost solar cells are expected in near future.

Here in this work, we have reported characteristics of $\mathrm{Si}-\mathrm{NW}$ on c-Si slab by numerical simulation and focused on the detrimental key factors such as absorption profile, energy flow, EM field distribution and exciton generation rate at band gap of ca. $1.7 \mathrm{eV}$ (i.e. $740 \mathrm{~nm}$ ). The excitation wavelength was considered as such because of strong irradiation of AM 1.5G solar spectra at this wavelength as well as being close to the band gap of c-Si and Si-NWs. It was revealed that Si-NW effectively confined and enhanced the absorption and energy flow distribution within the nanowire compared to those of flat slab c-Si at this wavelength. To the extent, the electric field distribution was found to be enhanced and spread all the way to the bottom of the wire. FDTD simulation also confirmed that the exciton generation rate is very high and spatially confined along the Si-NWs. An attempt is also reported to grow Si-NWs aligned vertically on c-Si wafer through a bottom-up technique. Nanoparticles-assisted CVD growth of Si-NWs provided a wide variation of sizes and diameters of nanowires. Scanning electron microscopy (SEM) micrographs confirmed Si-NWs of several microns length with 50-200 nm diameter.

\section{Materials and methodology}

A model was designed keeping the parameters very similar to those of as-fabricated Si-NW on c-Si wafer. For avoiding the complexity of simulation, a single Si-NW was modeled on $\mathrm{c}-\mathrm{Si}$ slab rather than an array and further investigation was focused on absorption profile, energy transfer profile, EM field distribution and exciton generation rate. The observations were compared to those obtained in flat c-Si slab without any Si-NWs. All the observations were carried out at $740 \mathrm{~nm}(1.7 \mathrm{eV})$ since $\mathrm{Si}$ NWs were reported to be highly crystalline with wide range of band gap as well as strong irradiation of AM 1.5 near this wavelength. FDTD package of Lumerical Solution was used to carry out the simulation.

Single side well-polished silicon (1-1-1 oriented, n-type phosphorus-doped, resistivity $<1 \Omega \mathrm{cm}$ ) wafer as received from Siltronix was degreased in acetone and isopropanol followed by copious rinses with Milli-Q water. The wafer was then immersed in $3: 1$ concentrated $\mathrm{H}_{2} \mathrm{SO}_{4} / 30 \%$ $\mathrm{H}_{2} \mathrm{O}_{2}$ for $15 \mathrm{~min}$ at $80^{\circ} \mathrm{C}$. An ultrathin layer of gold $(\mathrm{Au})$ film (ca. $4 \mathrm{~nm}$ thick) was deposited on $\mathrm{Si}$ wafer and the specimen was transferred in a CVD reactor. First, the sample was annealed at $700{ }^{\circ} \mathrm{C}$ to produce Au nanoparticles. The resulting surface was exposed to $\mathrm{SiH}_{4}$ gas for $30 \mathrm{~min}$ at $1.1 \mathrm{mbar}$ (flow of $\mathrm{H}_{2} / \mathrm{SiH}_{4}, \mathrm{QH}_{2} / \mathrm{SiH}_{4}=150$ / $12 \mathrm{sccm})$ and heated at high temperatures $\left(400-550{ }^{\circ} \mathrm{C}\right)$ to produce a dense array of nanowires (Schmidt et al. 2009; Suzuki et al. 2007; Wagner and Ellis 1964). A schematic diagram of the process is shown in Fig. 1 in brief. An ultrathin layer of $\mathrm{Au}$ on $\mathrm{c}-\mathrm{Si}$ wafer shown in Fig. 1a was turned into nanoparticles (Fig. 1b) by sintering. Figure 1c represents vertically aligned nanoparticlesassisted $\mathrm{Si}-\mathrm{NWs}$ grown on c-Si. As-grown $\mathrm{Si}-\mathrm{NWs}$ are further cleansed by the mixture of $\mathrm{HNO}_{3}$ and $\mathrm{HF}$ to remove nanoparticles as well as unexpected oxides as shown in Fig. 1d.

The resulting Si-NWs were characterized using SEM and tunneling electron microscope (TEM). The typical size of as-prepared Si-NWs was as long as few microns length. Depending on Au nanoparticles sizes, as-prepared Si-NWs were found to show a wide range of diameters. Elemental composition was confirmed by TEM-coupled energy dispersive spectroscopy (EDS).

\section{Results and discussion}

3D FDTD simulations were used to calculate the absorption, Poynting vector, electric field and exciton generation. The simulation geometry is depicted in Fig. 2. Figure 2a shows the dimension of the model comprised of Si-NW (1.7 $\mu \mathrm{m}$ long, $150 \mathrm{~nm}$ diameter), c-Si slab $(1 \mu \mathrm{m}$ thickness) and an underneath oxide layer $(200 \mathrm{~nm})$. A plane wave with a specific wavelength (i.e. $740 \mathrm{~nm}$ ) and polarization (transverse-magnetic (TM)) is modeled normally incident to c-Si slab and $\mathrm{Si}-\mathrm{NW}$ on slab as shown in 3D view in Fig. 2b. Monitors for calculating absorption and generation rate as well as simulation area is shown in 
Fig. 1 Free-hand schematic for $\mathrm{Si}$-NWs growth mechanism from ultrathin layer of $\mathrm{Au}$ on c-Si wafer. a Ultrathin layer of $\mathrm{Au}$ on $\mathrm{c}-\mathrm{Si}$, b sintering to form Au nanoparticles, c CVD growth of Si-NWs using silane source and $\mathbf{d}$ removal of $\mathrm{Au}$ and oxides by etching

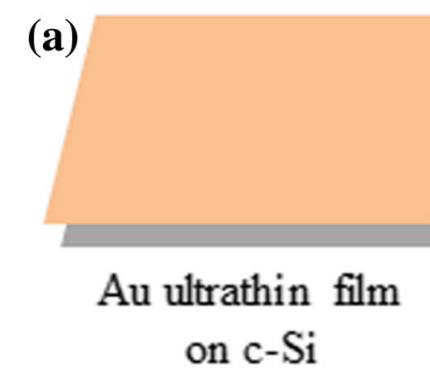

(c)

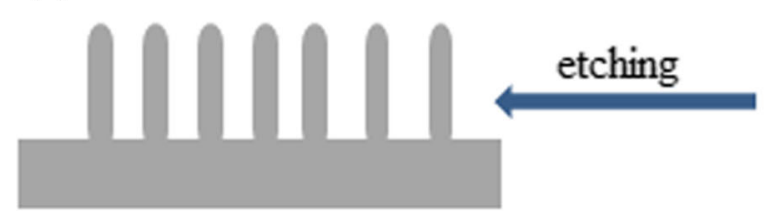

$\mathrm{Si}$ Nanowires on c-Si

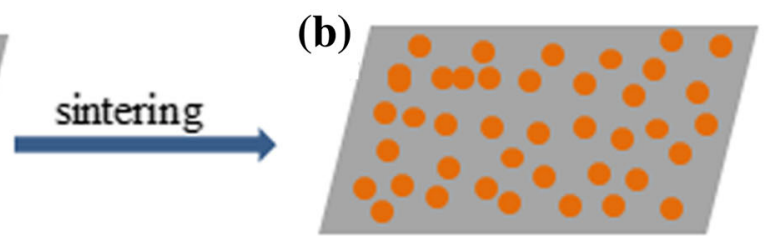

$\mathrm{Au}$ nanoparticles In CVD on $\mathrm{c}-\mathrm{Si}$

(d)

\section{$\mathrm{Au}$ nanoparticles-mediated $\mathrm{Si}$ Nanowires on $\mathrm{c}-\mathrm{Si}$}

Fig. 2 Si-NW geometry (not to the scale) modeled in this study. a Dimensions of the nanowire, c-Si slab and oxide layer, b materials and illumination area along with direction and polarization and $\mathbf{c}$ simulation area showing different monitors, such as source, absorption and generation rate calculation
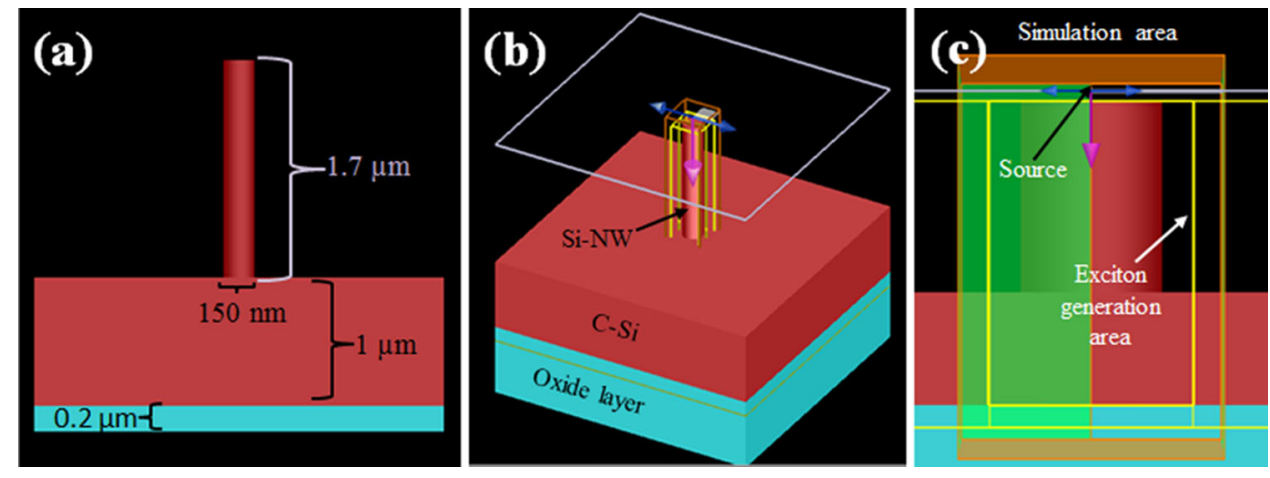

Fig. 2c. In FDTD simulation, electromagnetic field $(\vec{E}, \vec{H})$ are calculated with Maxwell's equations solver in time domain at each point on the 3D simulation grid.

Optical absorption properties of PV solar cells are critical to PV applications and therefore Si-NWs have received immense attention as efficient light absorbers. It has been demonstrated that $1 \% \mathrm{Si}$ material in the form of $\mathrm{Si}-\mathrm{NWs}$ is enough to provide similar amount of solar absorption absorbed by conventional c-Si-based $\mathrm{p}-\mathrm{n}$ junction solar cell. The strong light trapping ability of Si-NWs is the key factor that makes this enhancement and distributed generation rate all the way down to the bottom of Si-NWs. Simulated absorption profiles for c-Si slab without Si-NW and with Si-NW are shown in Fig. 3a, c, respectively. It was observed that Fabry-Perot like absorption mode occurred with regular pattern through the c-Si only. In case of Si-NWs on c-Si slab, this absorption is effectively confined within Si-NW as a more like Bloch-mode. It was also observed that this Bloch-mode like distribution highly depends on nanowire dimensions and geometry. As known, the absorption photons transfer energy from solar radiation to excite excitons within the semiconductor. Hence Poynting power flow, in fact, reflects the correlation between photon absorption and energy transfer. Poynting vectors for c-Si slab without $\mathrm{Si}-\mathrm{NW}$ and with $\mathrm{Si}-\mathrm{NW}$ are shown in Fig. 3b, d, respectively. In case of c-Si slab without Si-NW system, Fabry-Perot like energy flux distribution with regular pattern was observed similar to that observed in absorption distribution. On the contrary, for Si$\mathrm{NW}$ on c-Si slab system, energy flux got confined and locally distributed along the nanometric wire. To the extend, the energy flux distribution intensity decays slowly from top to all the way down to the bottom of Si-NW as shown in Fig. 3d. One of the plausible reasons could be due to nonlinear relationship between Poynting vector and electric field distribution (Chao et al. 2010; Tobías et al. 2008). As mentioned above, the wavelength $740 \mathrm{~nm}$ was considered in simulation since the absorption band gap of Si-NWs was reported to be ca. $1.7 \mathrm{eV}$ (i.e. $740 \mathrm{~nm}$ ) which is also close to n-type c-Si wafer. 
Fig. 3 Absorption and energy profile at $740 \mathrm{~nm}$ wavelength. a Fabry-Perot mode like distribution in c-Si slab without Si-NW, b Poynting energy flow distribution in c-Si slab without Si-NW, c confined and enhanced absorption distribution in $\mathrm{Si}-\mathrm{NW}$ on c-Si slab and $\mathbf{d}$ confined energy flow all along the way down to the bottom of Si-NW
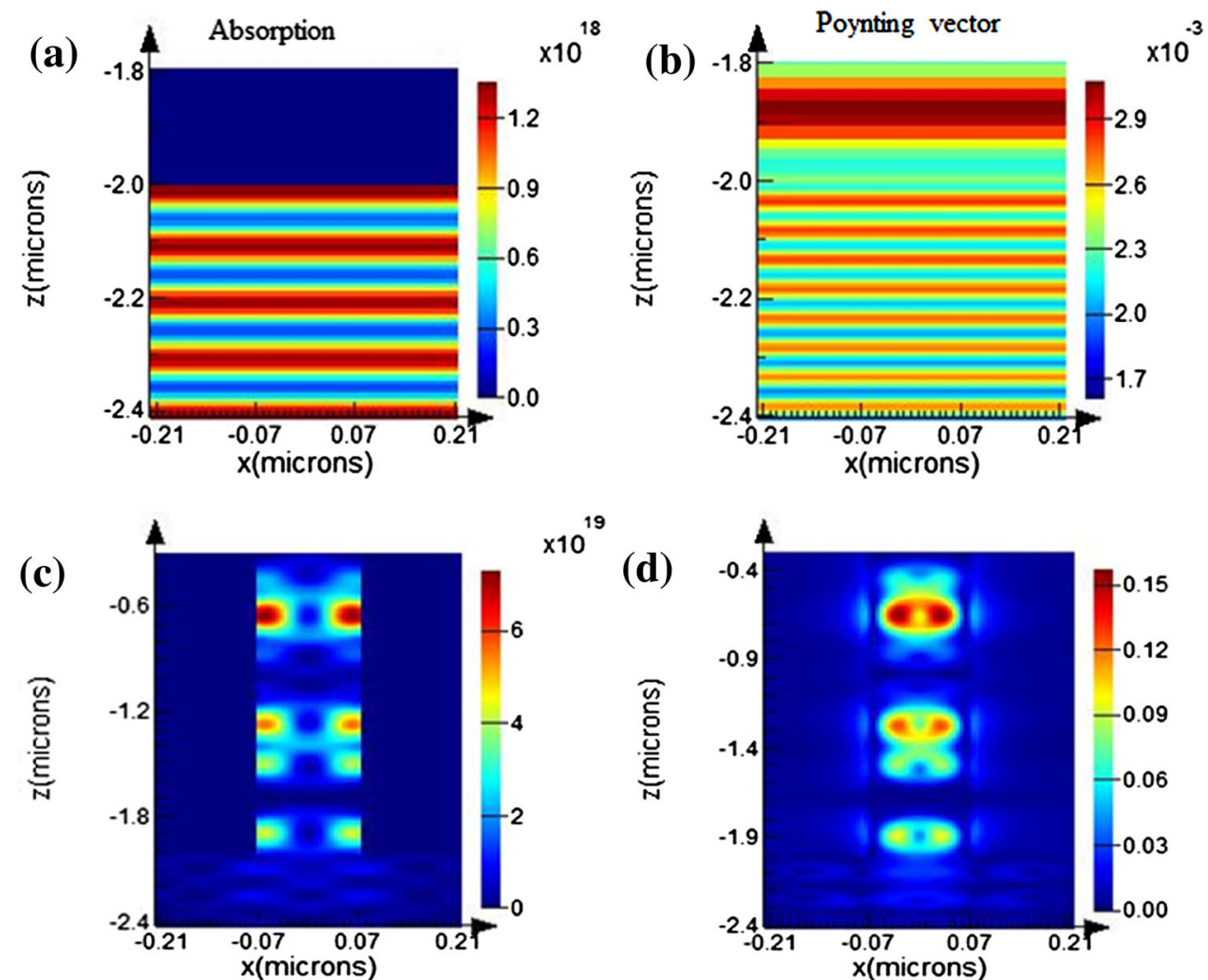

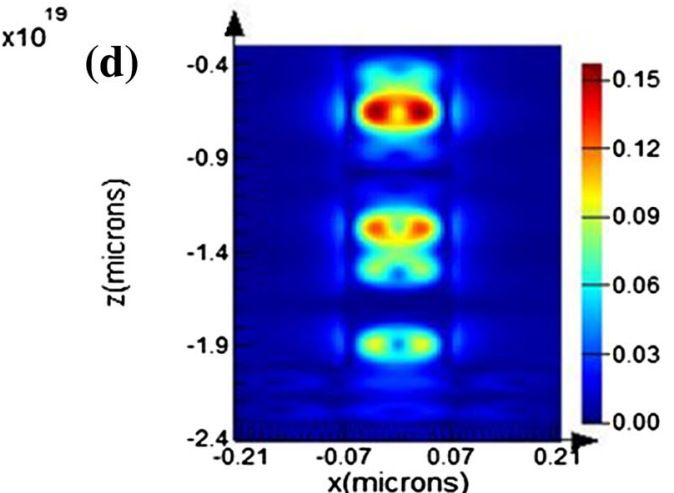

In semiconductor, photons are absorbed from electromagnetic waves of solar radiation and then this energy is used to excite free electron-hole pair. Therefore, electric field distribution defines how effectively excitons will be generated within the absorbing layer. Figure $4 \mathrm{a}$ shows simulated electric field distribution for c-Si slab without $\mathrm{Si}$ NW. Fabry-Perot mode like distribution was observed with regular pattern throughout the c-Si slab only. Interestingly, $\mathrm{Si}$-NW on c-Si slab showed confined and enhanced electric field distribution similar to that observed in Fig. 3c. From the divergence of Poynting energy flow, excitons generation rate can be simulated provided that all recombination process are considered negligible. It was revealed that generation rate was higher at the surface of $\mathrm{c}-\mathrm{Si}$ slab without $\mathrm{Si}-\mathrm{NW}$ as expected. In case of Si-NW on c-Si slab, generation rates distribution was observed to be enhanced and locally confined all along the Si-NW length.

As a part of experimental attempt, vertically aligned $\mathrm{Si}$ NWs were fabricated on c-Si wafer. Details of mechanisms and steps are stated already in experimental section. In brief the process consisted of four simple steps demonstrated in Fig. 1, viz, (1) ultrathin layer of Au coating on c-Si wafer, (2) sintering to turn the film into Au nanoparticles, (3) CVD to grow Au nanoparticles-assisted Si-NWs, and (4) removal of Au nanoparticles. SEM observations confirmed that as-fabricated Si-NWs are different in length and diameter as shown in Fig. 5. Figure 5a, b show typical
SEM micrographs of as-fabricated Si-NWs in c-Si wafer. Figure $5 \mathrm{c}$ represents a magnified view of a small crosssection marked by dotted white square in Fig. 5a. It is noteworthy that Si-NWs were grown nicely whereas some of the Au nanoparticles were remained unused as catalyst. In nanoparticles-assisted $\mathrm{Si}-\mathrm{NWs}$ growth nanowires are highly dependent on the size and shape of the seeds (i.e., Au nanoparticles here in this study). It was revealed clearly that different sizes of Au nanoparticles acted as catalyst to grow Si-NWs of various diameter ranging from 60 to $200 \mathrm{~nm}$ as shown in Fig. 5b. A clear peak of $\mathrm{Si}$ was observed in TEM-coupled EDS observations. Peaks for $\mathrm{Cu}$ were obtained due to copper grid of TEM measurements.

\section{Conclusion}

Si-NWs-based solar cell and/or tandem solar cell are very interesting and promising approach to low-cost and efficient photovoltaic devices. Here in this investigation, we had shown through FDTD simulation that Si-NWs on c-Si effectively enhanced absorption, energy distribution, electric profile, and generation rate with reference to those observed in c-Si slab without Si-NW. An experimental effort to achieve vertically aligned $\mathrm{Si}-\mathrm{NWs}$ on c-Si wafer was carried out. SEM observation confirmed that $\mathrm{Au}$ nanoparticles as seeds to grow $\mathrm{Si}-\mathrm{NWs}$ are indeed 
Fig. 4 Electric field and $740 \mathrm{~nm}$ wavelength. a, b Fabry-Perot mode like EM field and generation rate distribution in c-Si slab without Si-NW respectively, c confined and enhanced electric field distribution in $\mathrm{Si}-\mathrm{NW}$ on c-Si slab and $\mathbf{d}$ confined exciton generation rate distribution along the Si-NW length generation rate profile at
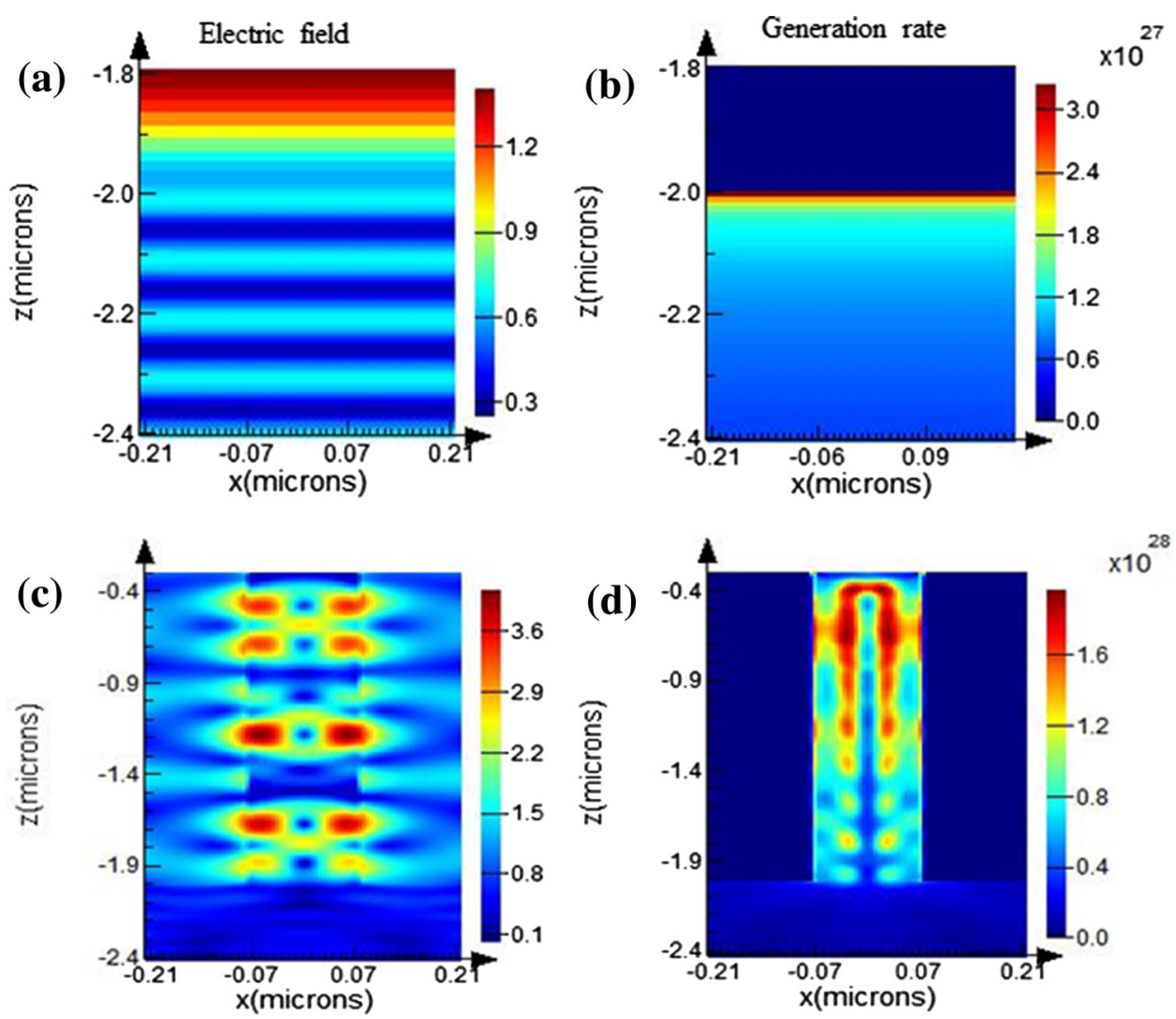

Fig. 5 SEM micrographs. a Wide view of as-fabricated $\mathrm{Si}$ NWs on c-Si wafer, $\mathbf{b}$ closeview of individual as-fabricated Si-NWs showing different dimensions in length and diameter, $\mathbf{c}$ Magnified images of the small area marked by white square in a and d TEM-coupled EDS to confirm the elemental composition of as-fabricated SiNWs on c-Si wafer

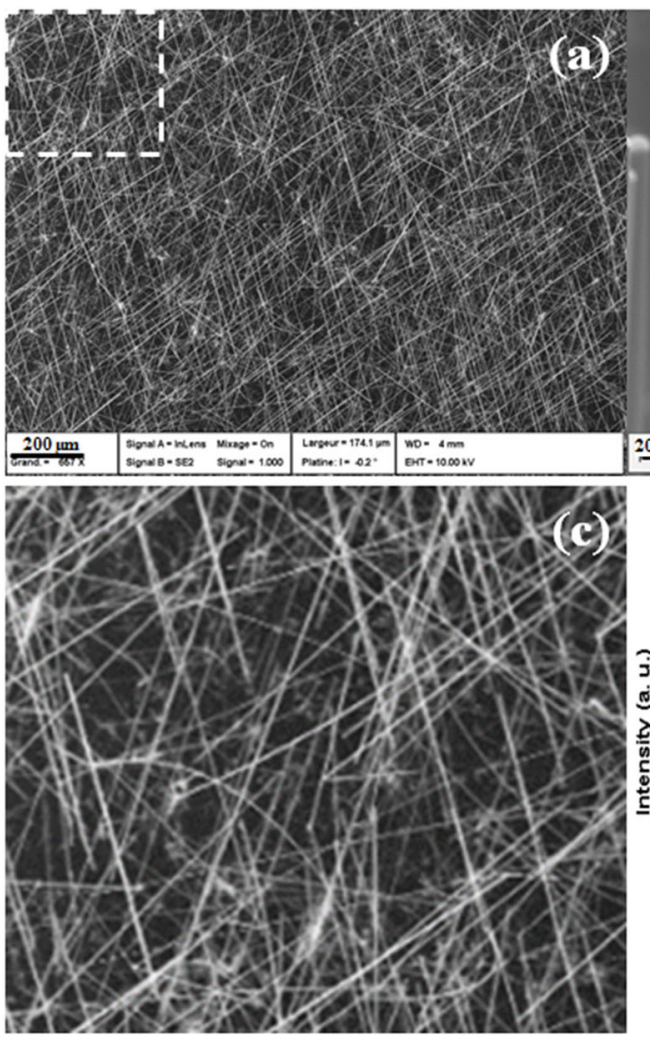

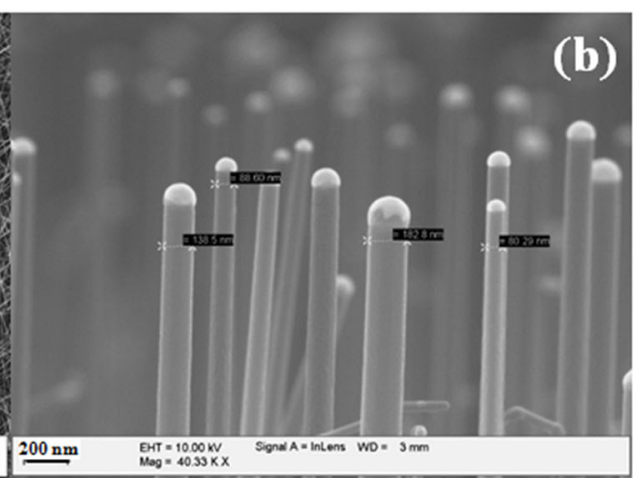

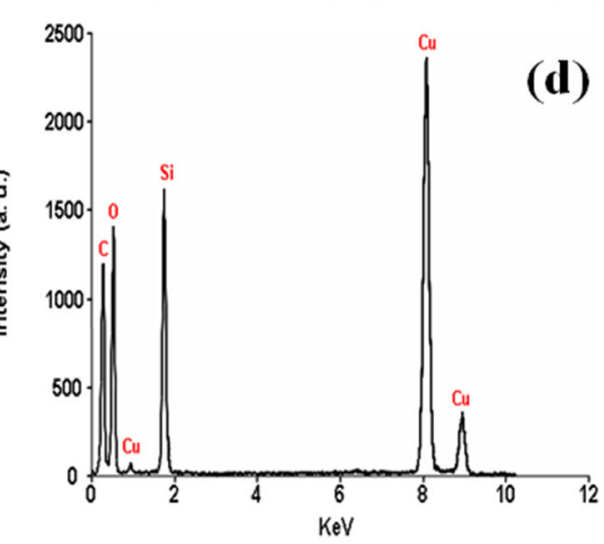


important elements to optimize nanowires length and diameter. TEM-coupled EDS also confirmed the elemental composition of as-fabricated $\mathrm{Si}-\mathrm{NWs}$ on c-Si wafer. Utilizing the inherent optical and geometrical properties of such Si-NWs, it is possible to design and develop next generation of thin film solar cell efficient enough to compete with traditional c-Si solar cells.

Acknowledgments The authors are thankful to Center of Research Excellence in Renewable Energy (CoRERE), King Fahd University of Petroleum and Minerals for the support in this work.

Open Access This article is distributed under the terms of the Creative Commons Attribution 4.0 International License (http:// creativecommons.org/licenses/by/4.0/), which permits unrestricted use, distribution, and reproduction in any medium, provided you give appropriate credit to the original author(s) and the source, provide a link to the Creative Commons license, and indicate if changes were made.

\section{References}

Bolman C, Coffey V, Fu B, Song J, Trangucci R, Zuboff G (2011) The true cost of solar power. Photon Consult, Boston

Chang YM, Shieh J, Juang JY (2012) Subwavelength antireflective si nanostructures fabricated by using the self-assembled silver metal-nanomask. J Phys Chem C 115:8983-8987

Chao C-C, Wang C-M, Chang J-Y (2010) Spatial distribution of absorption in plasmonic thin film solar cells. Opt Express 18:11763-11771

Chen H, Wang H, Zhang XH, Lee CS, Lee ST (2010) Wafer-scale synthesis of single-crystal zigzag silicon nanowire arrays with controlled turning angles. Nano Lett 10:864-868

Cho SJ, An T, Kim JY, Sung J, Lim G (2011) Superhydrophobic nanostructured silicon surfaces with controllable broadband reflectance. Chem Commun 47:6108-6110

Garnett E, Yang P (2010) Light trapping in silicon nanowire solar cells. Nano Lett 10:1082-1087

Geyer N, Fuhrmann B, Huang Z, de Boor J, Leipner HS, Werner P (2012) Model for the mass transport during metal-assisted chemical etching with contiguous metal films as catalysts. J Phys Chem C 16:13446-13451

Green MA (2014) Silicon solar cells: state of the art. Philos Trans R Soc A 371:20110413-20110428

He L, Jiang C, Lai D, Wang H, Rusli R (2012) Enhanced conversion efficiency for si nanowire-organic hybrid solar cells through the incorporation of organic small molecule. Jpn J Appl Phys $51: 10 \mathrm{NE} 36$

Huang Z, Zhang X, Reiche M, Liu L, Lee W, Shimizu T, Senz S, Gosele U (2008) Extended arrays of vertically aligned sub$10 \mathrm{~nm}$ diameter [100] si nanowires by metal-assisted chemical etching. Nano Lett 8:3046-3051

Kelzenberg MD, Boettcher SW, Petykiewicz JA, Turner-Evans DB, Putnam MC, Warren EL, Spurgeon JM, Briggs RM, Lewis NS, Atwater HA (2010) Enhanced absorption and carrier collection in $\mathrm{Si}$ wire arrays for photovoltaic applications. Nat Mater 9:239-244

Krogstrup P, Jorgensen HI, Heiss M, Demichel O, Holm JV, Aagesen M, Nygard J, Morral AF (2013) Single-nanowire solar cells beyond the Shockley-Queisser limit. Nat Photon 7:306-310

Krylyuk S, Davydov AV, Levin I (2010) Tapering control of si nanowires grown from $\mathrm{SiCl}_{4}$ at reduced pressure. ACS Nano 5:656-664

Moutanabbir O, Senz S, Scholz R, Alexe M, Kim Y, Pippel E, Wang Y, Wiethoff C, Nabbefeld T, Heringdorf FM, Hoegen MH (2011) Atomically smooth p-doped silicon nanowires catalyzed by aluminum at low temperature. ACS Nano 5:1313-1320

Ozdemir B, Kulakci M, Turan R, Unalan H (2011) Silicon nanowirepoly (3,4-ethylenedioxythiophene)-poly (styrenesulfonate) heterojunction solar cells. Appl Phys Lett 99:113510-1113510-3

Polman A, Atwater HA (2012) Photonic design principles for ultrahigh-efficiency photovoltaics. Nat Mater 11:174-177

Sachs G (2011) Goldman Sachs research report. Goldman Sachs, New York

Sainiemi L, Jokinen V, Shah A, Shpak M, Aura S, Suvanto P, Franssila S (2011) Non-reflecting silicon and polymer surfaces by plasma etching and replication. Adv Mater 23:122-126

Schmidt V, Wittemann JV, Senz Gosele U (2009) Silicon nanowires: a review on aspects of their growth and their electrical properties. Adv Mater 21:2681-2702

Shin N, Filler MA (2012) Controlling silicon nanowire growth direction via surface chemistry. Nano Lett 12:2865-2870

Suzuki H, Araki H, Tosa M, Noda T (2007) Formation of silicon nanowires by CVD using gold catalysts at low temperatures. Mater Trans 48:2202-2206

Tobías I, Luque A, Martí A (2008) Light intensity enhancement by diffracting structures in solar cells. J Appl Phys 104:034502$1-034502-9$

Wagner RS, Ellis WC (1964) Vapor-liquid-solid mechanism of single crystal growth. Appl Phys Lett 4:89-90

Xiao S, Xu S (2014) High-efficiency silicon solar cells-materials and devices physics. Crit Rev Solid State 39:277-317

Yi J, Lee DH, Park WI (2011) Site-specific design of cone-shaped Si nanowires by exploiting nanoscale surface diffusion for optimal photoabsorption. Chem Mater 23:3902-3906

Yu LW, Misra S, Wang JZ, Qian SY, Foldyna M, Xu J, Shi Y, Johnson E, Cabarrocas PR (2014) Understanding light harvesting in radial junction amorphous silicon thin film solar cells. Sci Rep 4:4357-4363

Yuan G, Mitdank R, Mogilatenko A, Fischer SF (2012) Porous nanostructures and thermoelectric power measurement of electro-less etched black silicon. J Phys Chem C 116:13767-13773

Zhao X, Wei CM, Yang L, Chou MY (2004) Quantum confinement and electronic properties of silicon nanowires. Phys Rev Lett 92:236805-1-236805-4

Zhong X, Qu Y, Lin YC, Liao L, Duan X (2011) Unveiling the formation pathway of single crystalline porous silicon nanowires. ACS Appl Mater Interface 3:261-270

Zhu J, Yu Z, Burkhard GF, Hsu CM, Connor ST, Xu Y, Wang Q, McGehee M, Fan S, Cui Y (2009) Optical absorption enhancement in amorphous silicon nanowire and nanocone arrays. Nano Lett 9:279-282 